\title{
Distribution of Microcrystalline Quartz in Glassy Fulgurites from Garuamukh and Kimin, India
}

\author{
Bhaskar J. Saikia1, G. Parthasarathy', Rashmi R. Borah ${ }^{3}$ \\ ${ }^{1}$ Department of Physics, Anandaram Dhekial Phookan College, Nagaon, India \\ ${ }^{2}$ National Geophysical Research Institute (Council of Scientific and Industrial Research), Hyderabad, India \\ ${ }^{3}$ Department of Physics, Nowgong College, Nagaon, India \\ Email: vaskar r@rediffmail.com
}

Received 15 September 2015; accepted 26 October 2015; published 29 October 2015

Copyright (C) 2015 by authors and Scientific Research Publishing Inc.

This work is licensed under the Creative Commons Attribution International License (CC BY). http://creativecommons.org/licenses/by/4.0/

C) (i) Open Access

\begin{abstract}
The presence of microcrystalline quartz particles in fulgurites of Garuamukh and Kimin has been investigated. The compositional and structural studies were carried out at room temperature by using X-ray fluorescence (XRF), X-ray diffraction (XRD) and Fourier transform infrared (FTIR) spectroscopic techniques. The compositional result shows the major constituent of the fulgurites to be $\mathrm{SiO}_{2}$ with miniature quantities of oxides of $\mathrm{Al}, \mathrm{Ti}, \mathrm{Fe}, \mathrm{Ca}$, and $\mathrm{Na}$. The $\mathrm{X}$-ray diffraction quantified the mixtures of identical amorphous and micro-crystalline phases in the fulgurites samples. Systemetatic investigations of microcrystalline quartz particles have been carried out in midinfrared region of $500-1000 \mathrm{~cm}^{-1}$ based on the assignment of infrared bands of the structural group $\mathrm{SiO}_{4}$ tetrahedra. In infrared $\mathrm{Si}-\mathrm{O}-\mathrm{Si}$ bending vibration region of quartz, the octahedral characteristic peak is explored in the fulgurites samples with the variation of the particle sizes which is indicative to the presence of microcrystalline quartz. The distribution of the microcrystalline quartz is ascertained by calculating the extinction coefficient. The present study has significant implications in understanding the thermodynamic properties of naturally occurring glasses, which are formed by shock metamorphism.
\end{abstract}

Keywords

Fulgurites, Microcrystalline Quartz, Spectroscopic Method

\section{Introduction}

Numbers of phenomena are responsible for making natural glass on Earth including meteorite impact, lightning

How to cite this paper: Saikia, B.J., Parthasarathy, G. and Borah, R.R. (2015) Distribution of Microcrystalline Quartz in Glassy Fulgurites from Garuamukh and Kimin, India. Journal of Applied Mathematics and Physics, 3, 1343-1351.

http://dx.doi.org/10.4236/jamp.2015.310161 
and volcanic activity. The glassy object made as a result of a cloud-to-ground lightning discharge is called fulgurites. A typical lightning strike may disperse up to $1 \mathrm{GJ}$ per flash and a small fraction of it ( 1 MJ) reaches the ground [1]. It is accompanied by temperatures momentarily reaching between 18,000 and 39,000 K depending on moisture content in the air and this temperature is tremendously higher than the melting point of silica [1] [2]. This energy raises the temperature and pressure of the ground mass (soil, sand or rock) in the lightning channel accelerating material in and around the channel radially outward. It results in shock metamorphic effects. The silicaceous components of the sand, soil, or rock fused to form solidified glass and a fragile hollow tube with a diameter of a few centimeters and a length that can vary from centimeters to meters [3] [4]. The outer surface of fulgurites is recognized to partly melt fragments of minerals and rocks that are incorporated into its structure [5]. The interior surface is smooth and glassy and may also contain trap gas inclusions from the surrounding area [6]. The chemical composition of fulgurites is depending upon the nature of the abundant minerals of surrounding environment [4] [5] [7]. The mineralogical composition (lechatelirite, cristobalite, chalcedony, opal) of fulgurites is related to the palaeo-environmental conditions of the semi-arid regions and to the melting conditions during the fulgurites forming lightning strike to the ground. Fulgurites are also very resistant to weathering and hence the study of properties of fulgurites may be helpful in understanding the ultra-high temperature natural phenomena during lightning [8]. Several putative impacts have been proposed based on the presence of shocked quartz in glassy samples alone [9]-[11]. Quartz is one of the most commonly used indicator minerals for shock metamorphism, as well as for pressure calibration. Quartz displays a wide variety of shock-induced mechanical deformations and transformations [12]-[16]. The studied fulgurites samples reveal the characteristic features of amorphous silica with some microcrystalline quartz and other minerals as trace [17] [18]. The structure of most $\mathrm{SiO}_{2}$ polymorphous, both crystalline and amorphous, is based on $\mathrm{SiO}_{4}$ tetrahedra. Amorphous silica is one of the polymorphous silica and at high temperature it can easily transform from quartz. In the Si-O-Si bending vibration region (400-700 $\mathrm{cm}^{-1}$ ) of quartz, the band at $695 \mathrm{~cm}^{-1}$ is determinative whether it is crystalline or amorphous [18]-[20]. In the present work, we address the infrared technique for estimation of micro-crystallinity of quartz in fulgurites. The sample has been characterized by powder X-ray diffraction, X-ray fluorescence and Fourier transform infrared (FT-IR) spectroscopic methods.

\section{Materials and Methods}

\subsection{Fulgurite Samples}

Fraction of two fulgurites samples are collected from Garuamukh near Nagaon town (latitude $26^{\circ} 20^{\prime} \mathrm{N}$, longitude $92^{\circ} 41^{\prime} \mathrm{E}$, Assam, India) and Kimin, near Itanagar (latitude $27^{\circ} 06^{\prime} \mathrm{N}$, longitude $93^{\circ} 39^{\prime} \mathrm{E}$, Arunachal Pradesh, India) for spectroscopic analysis. Each fulgurite sample comprising dark heterogeneous glassy material containing several white and greyish-brown areas (Figure 1). The total mass of the Garuamukh and Kimin fulgurite was estimated to be more than $10 \mathrm{~kg}$ and $30 \mathrm{~kg}$ respectively with numbers of individual pieces. On the basis of its physical attributes, these fulgurites can be classified as type II fulgurite.

\subsection{Sampling and Analysis}

A part of the samples are crushed into $>90 \mu \mathrm{m}, 90-63 \mu \mathrm{m}, 63-45 \mu \mathrm{m}$ and $<45 \mu \mathrm{m}$ fractions using mechanical sieve according to the Indian standard (IS 1607:2013) [21]. The smallest size achieved by a mechanical sieve is a $45 \mu \mathrm{m}$ fraction. This fraction is sieved through a $45 \mu$ sieve, where the $<45 \mu \mathrm{m}$ particles are obtained. We tried to minimize the grinding time to avoid the deformation of the crystal structure and the ion exchange. Powdered samples (0.25 g) are put into platinum crucibles and $\mathrm{HNO}_{3}$ (conc.), $\mathrm{HCl}, \mathrm{H}_{2} \mathrm{O}_{2}$ and $\mathrm{HF}$ are added in a proportion of 5:2:1:2 ml. Crucibles are heated on hot plate and the solution evaporated to near dryness. After that $2 \mathrm{ml} H \mathrm{HF}$ are added in each samples few times until precipitate of $\mathrm{SiO}_{2}$ is eliminated as $\mathrm{SiF}_{4}$ vapors. After cooling down to the room temperature, a mixture of $\mathrm{HCl}$ (conc.) and redistilled water at a ratio 2:5 ml are added, the solutions transferred in $50 \mathrm{ml}$ volumetric flasks and filled up with redistilled water. Then $0.5 \mathrm{~g}$ of powdered sample is put in a glass beaker and a mixture of redistilled water and $\mathrm{HCl}$ (conc.) in a ratio 15:20 ml is added and the solution evaporated to near dryness. The residue is dissolved with $10 \mathrm{ml} 1 \%$ tin, and $\mathrm{SiO}_{2}$ precipitated and coagulated. Precipitate is filtered and washed with $\mathrm{HCl}$ solution in a ratio 5:95 ml. Filter paper and residue are transferred into a platinum crucible and heated on $1000^{\circ} \mathrm{C}$ for $10 \mathrm{~min}$. Crucible is weighed and the content of $\mathrm{SiO}_{2} \mathrm{calcu}^{-}$ lated. The different sized powdered sample was homogenized in spectrophotometric grade $\mathrm{KBr}(1: 20)$ in an 

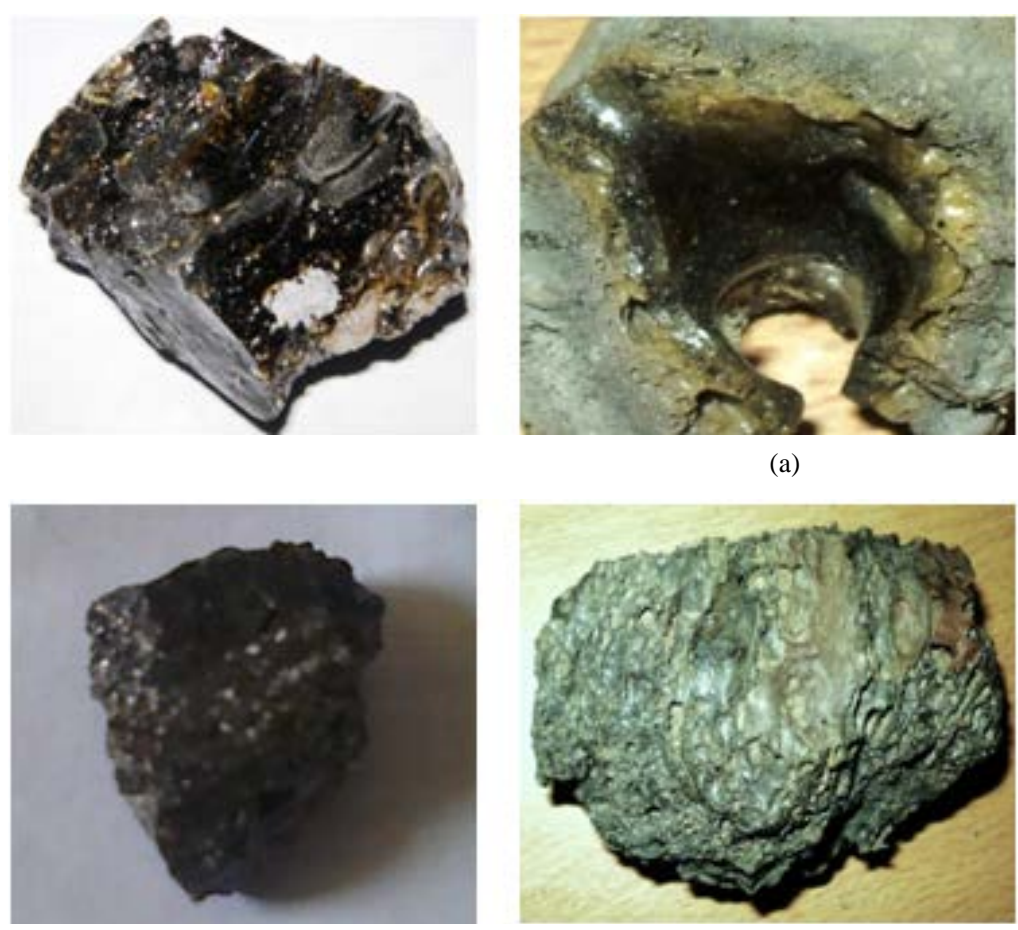

(b)
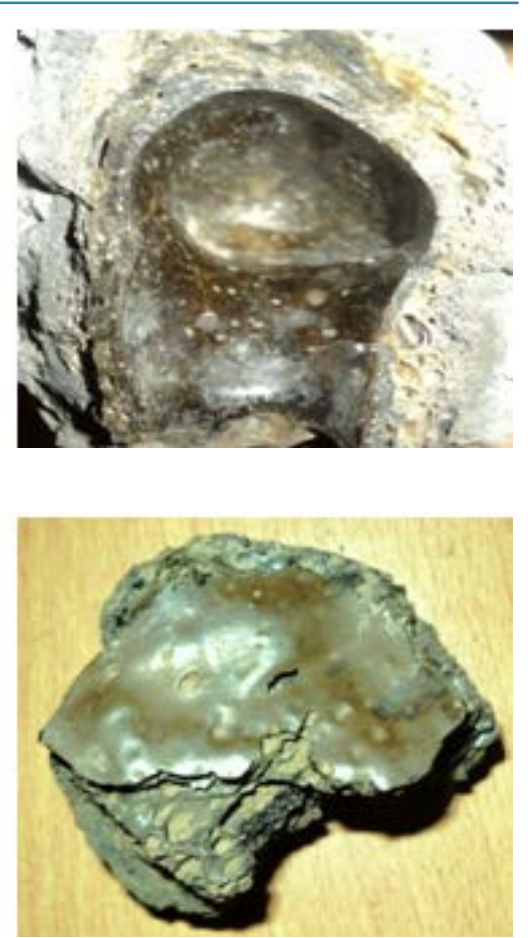

Figure 1. The photographs of three different fractions of Garuamukh and Kimin fulgurites. (a) Garuamukh; (b) Kimin.

agate mortar and was pressed with $3 \mathrm{~mm}$ pellets using hand press. The infrared spectra was acquired using Perkin-Elmer system 2000 FTIR spectrophotometer with helium-neon laser as the source reference, at a resolution of $4 \mathrm{~cm}^{-1}$. The spectra were taken in transmission mode in the region $400-4000 \mathrm{~cm}^{-1}$. The room temperature was $30^{\circ} \mathrm{C}$ during the experiment. A part of samples (different particle sized) were mixed with a small amount of acetone and pipetted out onto a glass slide for X-ray diffraction (XRD) analysis. The glassy nature of the samples were confirmed by powder X-ray diffraction (XRD) analysis, by using the Philips PW 3710 XRD system which was operated at $40 \mathrm{KV}$ and $45 \mathrm{~mA}$ between 5 and $75^{\circ} 2 \theta$ at a scan speed of $0.04^{\circ} 2 \theta / \mathrm{s}$, with a $\mathrm{CuK} \alpha(\lambda=$ $1.54 \AA$ ) radiation and a graphite monochromator. The composition of the fulgurites was determined by using Philips X-ray fluorescence (XRF) machine. In X-ray fluorescence method, typical uncertainty involved in oxide analyses was about $0.01 \mathrm{wt} \%$.

\subsection{Crystallinity and Extinction Coefficient}

The crystallinity indices are ascertained form the infrared spectra using the ratio of the optical densities of stretching mode at around $778 \mathrm{~cm}^{-1}$ and the bending mode at around $695 \mathrm{~cm}^{-1}$. The optical density $(D)$ is defined as the logarithm to the base 10 of the reciprocal of the transmitted radiant power $(T)$. The estimation of the relative distribution of microcrystalline quartz in the studied samples is ascertained by calculating the extinction coefficient for the characteristic peak at $778 \mathrm{~cm}^{-1}$ using the relation:

\section{Extinction coefficient $(K)=\mathrm{DA} / \mathrm{m}$}

where $A$ is the area of the pellet and $m$ the mass of the sample [20].

\section{Results and Discussions}

\subsection{Chemical Compositions of Fulgurites}

Figure 1 presents the photograph of fulgurite samples, which is composed of dark heterogeneous glassy material containing several white and yellowish-brown spot regions with prominent gas bubbles trapped within glassy regions. The elemental compositions as determined by X-ray fluorescence spectroscopy of the Garuamukh and 
Kimin fulgurites are presented in the Table 1 . The compositional and mineralogical results show the major constituent of the fulgurites to be $\mathrm{SiO}_{2}$ with miniature quantities of aluminium, titanium, iron, calcium and sodium oxides. The compositional results are compared with that of the previous work on fulgurites found elsewhere in similar occurrences [22]. The elemental composition of the samples (Table 2) exhibits low abundances of Ti, $\mathrm{Na}, \mathrm{Fe}, \mathrm{Mg}, \mathrm{K}$ and $\mathrm{Ca}$ and relatively high abundances of $\mathrm{Si}$ and $\mathrm{Al}$. The presence of $\mathrm{CaO}$ and $\mathrm{Na}_{2} \mathrm{O}$ in the studied samples is indicative of plagioclase grain.

Table 1. Comparison of chemical compositions of the studied fulgurites with other fulgurites.

\begin{tabular}{|c|c|c|c|c|c|c|c|c|}
\hline \multirow{2}{*}{ Occurrence Location } & \multicolumn{8}{|c|}{ Composition (wt\%) } \\
\hline & $\mathrm{SiO}_{2}$ & $\mathrm{Fe}_{2} \mathrm{O}_{3}$ & $\mathrm{Al}_{2} \mathrm{O}_{3}$ & $\mathrm{TiO}_{2}$ & $\mathrm{CaO}$ & $\mathrm{MgO}$ & $\mathrm{Na}_{2} \mathrm{O}$ & $\mathrm{K}_{2} \mathrm{O}$ \\
\hline Kimin (K-1) (Present study) & 97.23 & 0.84 & 1.98 & 0.56 & 0.02 & 0.02 & 0.04 & -- \\
\hline Kimin (K-2) (Present study) & 97.10 & 0.75 & 1.98 & 0.40 & 0.02 & 0.01 & 0.02 & -- \\
\hline Kimin (K-3) (Present study) & 96.90 & 0.70 & 1.90 & 0.55 & 0.01 & 0.01 & 0.04 & -- \\
\hline Kimin (K-4) (Present study) & 97.31 & 0.69 & 1.88 & 0.47 & 0.02 & 0.01 & 0.02 & -- \\
\hline Garuamukh (G-1) (Present study) & 97.17 & 0.70 & 1.67 & 0.47 & 0.02 & -- & 0.01 & 0.01 \\
\hline Garuamukh (G-2) (Present study) & 97.00 & 0.61 & 1.85 & 0.40 & 0.05 & -- & 0.05 & 0.03 \\
\hline Garuamukh (G-3) (Present study) & 97.38 & 0.80 & 1.70 & 0.05 & 0.01 & -- & 0.02 & 0.01 \\
\hline Garuamukh (G-3) (Present study) & 97.40 & 0.80 & 1.73 & 0.05 & 0.01 & -- & 0.02 & 0.01 \\
\hline Germany & 93.80 & -- & 3.80 & -- & 0.60 & -- & -- & -- \\
\hline South Amboy, New Jersey & 99.00 & 0.30 & 0.70 & -- & -- & -- & -- & -- \\
\hline Illinois & 91.66 & -- & 6.69 & -- & 0.38 & 0.12 & 0.77 & 0.73 \\
\hline Holland & 90.20 & 0.70 & 0.90 & -- & 0.10 & 0.50 & 0.60 & 0.50 \\
\hline Libyan Desert & 97.58 & -- & 1.54 & -- & 0.38 & -- & 0.34 & -- \\
\hline Little Ararat & 58.59 & 4.47 & 21.29 & -- & 6.36 & 2.49 & 4.42 & 0.94 \\
\hline Morocco & 91.60 & 0.76 & 2.30 & 0.45 & 0.14 & 0.17 & 0.06 & 0.63 \\
\hline New South Wales, Australia & 98.38 & 0.02 & 0.02 & 0.02 & 0.01 & -- & 0.01 & 0.01 \\
\hline Quartzite, Arizona & 59.70 & 5.50 & 16.4 & 0.87 & 6.40 & 2.30 & 2.70 & 3.70 \\
\hline Vernal, Utah & 58.10 & 5.50 & 15.5 & 0.93 & 8.00 & 4.10 & 4.04 & 2.60 \\
\hline Chaffee County, Colorado & 60.40 & 5.90 & 20.80 & 0.86 & 0.59 & 2.29 & 2.13 & 7.00 \\
\hline
\end{tabular}

Results are compared with the findings of Frondel (1962).

Table 2. Elemental compositions (\%wt) of Kimin and Garuamukh fulgurites.

\begin{tabular}{|c|c|c|c|c|c|c|c|c|c|c|}
\hline \multirow{2}{*}{ Elements } & \multicolumn{5}{|c|}{ Kimin } & \multicolumn{5}{|c|}{ Gruamukh } \\
\hline & K-1 & K-2 & K-3 & K-4 & Average & G-1 & G-2 & G-3 & G-4 & Average \\
\hline $\mathrm{Si}$ & 45.46 & 45.39 & 45.30 & 45.49 & 45.41 & 45.43 & 45.35 & 45.53 & 45.53 & 45.46 \\
\hline $\mathrm{Fe}$ & 0.65 & 0.52 & 0.49 & 0.48 & 0.54 & 0.54 & 0.47 & 0.62 & 0.62 & 0.57 \\
\hline $\mathrm{Al}$ & 1.05 & 1.05 & 1.01 & 0.99 & 1.02 & 0.88 & 0.98 & 0.90 & 0.92 & 0.92 \\
\hline $\mathrm{Ti}$ & 0.34 & 0.24 & 0.33 & 0.28 & 0.30 & 0.28 & 0.24 & 0.03 & 0.03 & 0.15 \\
\hline $\mathrm{Ca}$ & 0.01 & 0.01 & 0.01 & 0.01 & 0.01 & 0.01 & 0.04 & 0.01 & 0.01 & 0.02 \\
\hline $\mathrm{Mg}$ & 0.01 & 0.01 & 0.01 & 0.01 & 0.01 & -- & -- & -- & -- & -- \\
\hline $\mathrm{Na}$ & 0.03 & 0.01 & 0.03 & 0.01 & 0.02 & 0.01 & 0.04 & 0.01 & 0.01 & 0.02 \\
\hline K & -- & -- & -- & -- & -- & 0.01 & 0.02 & 0.02 & 0.01 & 0.02 \\
\hline
\end{tabular}




\subsection{Characterization of Microcrystalline Quartz}

Mixtures of identical amorphous and micro-crystalline phases has been identified or quantified in the fulgurites samples using X-ray diffraction. The X-ray diffraction patterns of the fulgurites samples are shown in Figure 2 and different size fractions displays nearly constant diffraction pattern. Both quartz and cristobalite are often present in trace amounts in fused silica. The crystalline phases of micro-crystalline quartz and cristobalite are generally observed on the hump produced in the diffraction pattern by the amorphous silica. The broad hump

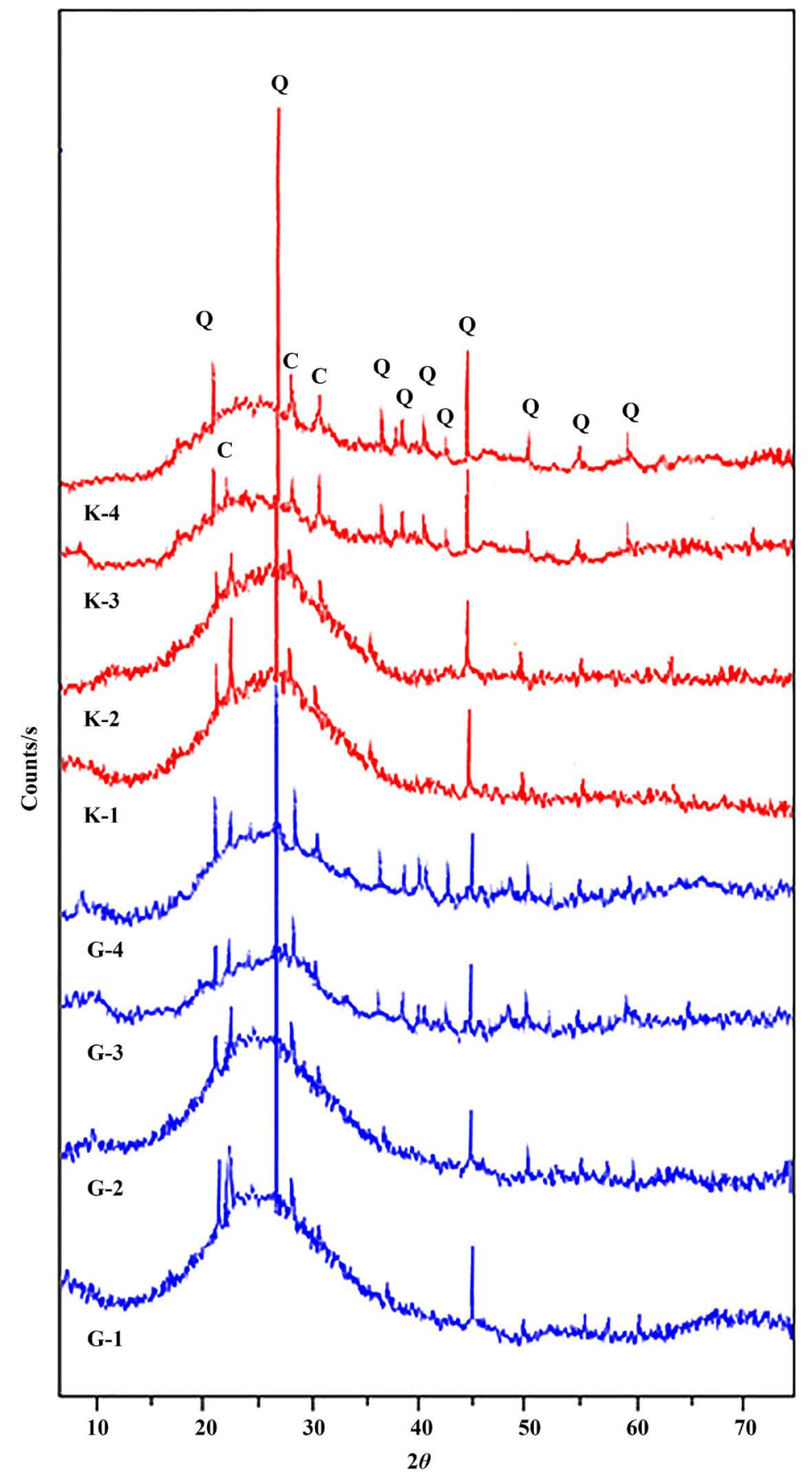

Figure 2. The X-ray diffraction patterns indicate quartz $(\mathrm{Q})$ and cristobalite (C) phases in the Kimin and Garuamukh fulgurites. 
observed in all spectra at around $18-36^{\circ} 2 \theta$ corresponds to a bulk composition of amorphous silica. Similar hump around $23^{\circ} 2 \theta$ in the Garuamukh fulgurites corresponding to the amorphous matrix of $\mathrm{SiO}_{2}$ was also observed in the previous studies [18] [19]. The very strong peaks observed in all spectra at around $26^{\circ} 2 \theta$ are due to the microcrystalline quartz. Another strong feature of microcrystalline quartz is observed at $20.8^{\circ} 2 \theta$ and $45^{\circ} 2 \theta$. A strong feature at around $21.8^{\circ} 2 \theta$ in the spectra is reported as the presence of the silica polymorph cristobalite with further minor features between $28-31^{\circ} 2 \theta$ may be due to the presence of coesite. Further weak but distinct peaks of microcrystalline quartz were noted at around $36^{\circ} 2 \theta, 39^{\circ} 2 \theta, 40^{\circ} 2 \theta, 42^{\circ} 2 \theta, 50^{\circ} 2 \theta, 54^{\circ} 2 \theta$ and $57^{\circ} 2 \theta$. The possible effects of the hematite inclusions corresponding to the peaks at around $36^{\circ} 2 \theta$ and $54^{\circ} 2 \theta$ cannot be ignored.

Figure 3 shows the infrared spectra of different particle sizes of the Garuamukh and Kimin fulgurites in the frequency range $500-2000 \mathrm{~cm}^{-1}$. The mid infrared spectra of silicate in between the range $1200-400 \mathrm{~cm}^{-1}$ are generally classified into four characteristic bands i.e. at $1080-1175 \mathrm{~cm}^{-1}$ are arises due to Si-O asymmetrical stretching vibration ( $v 3), 780-800 \mathrm{~cm}^{-1}$ is arises due to Si-O symmetrical stretching vibration $(v 1), 695 \mathrm{~cm}^{-1}$ is arise due to Si-O symmetrical bending vibration ( $v 2$ ), and $464 \mathrm{~cm}^{-1}$ is arise due to $\mathrm{Si}-\mathrm{O}$ asymmetrical bending vibration ( $v 4$ ) [23]. In the spectra of different particle sizes of fulgurites, the observed Si-O stretching vibration region at $785-787,952-965,1069-1080,1170-1174 \mathrm{~cm}^{-1}$ are identical to the bands at $800,958,1088 \mathrm{~cm}^{-1}$ arise due to amorphous silica [24].

Among these four characteristic peak regions, the Si-O symmetrical bending vibrational peak at $695 \mathrm{~cm}^{-1}$ of the octahedral site symmetry is unique to the crystalline materials. It is well known that in the infrared spectra of amorphous silica the symmetrical bending vibration of the $\mathrm{Si}-\mathrm{O}$ group found at $695 \mathrm{~cm}^{-1}$ is absent. Amorphous silica is one of the polymorphous of silica and at high temperature it can easily transform from quartz. Amorphous silica exhibits a relatively moderately strong peak at $800 \mathrm{~cm}^{-1}$ and it can be distinguished from the band of crystalline silicate [24]. Therefore, the symmetrical bending vibration of Si-O group obtained at $695 \mathrm{~cm}^{-1}$ is the diagnostic peak in determining the short range parameter of the quartz, whether it is crystalline or amorphous [20] [25].
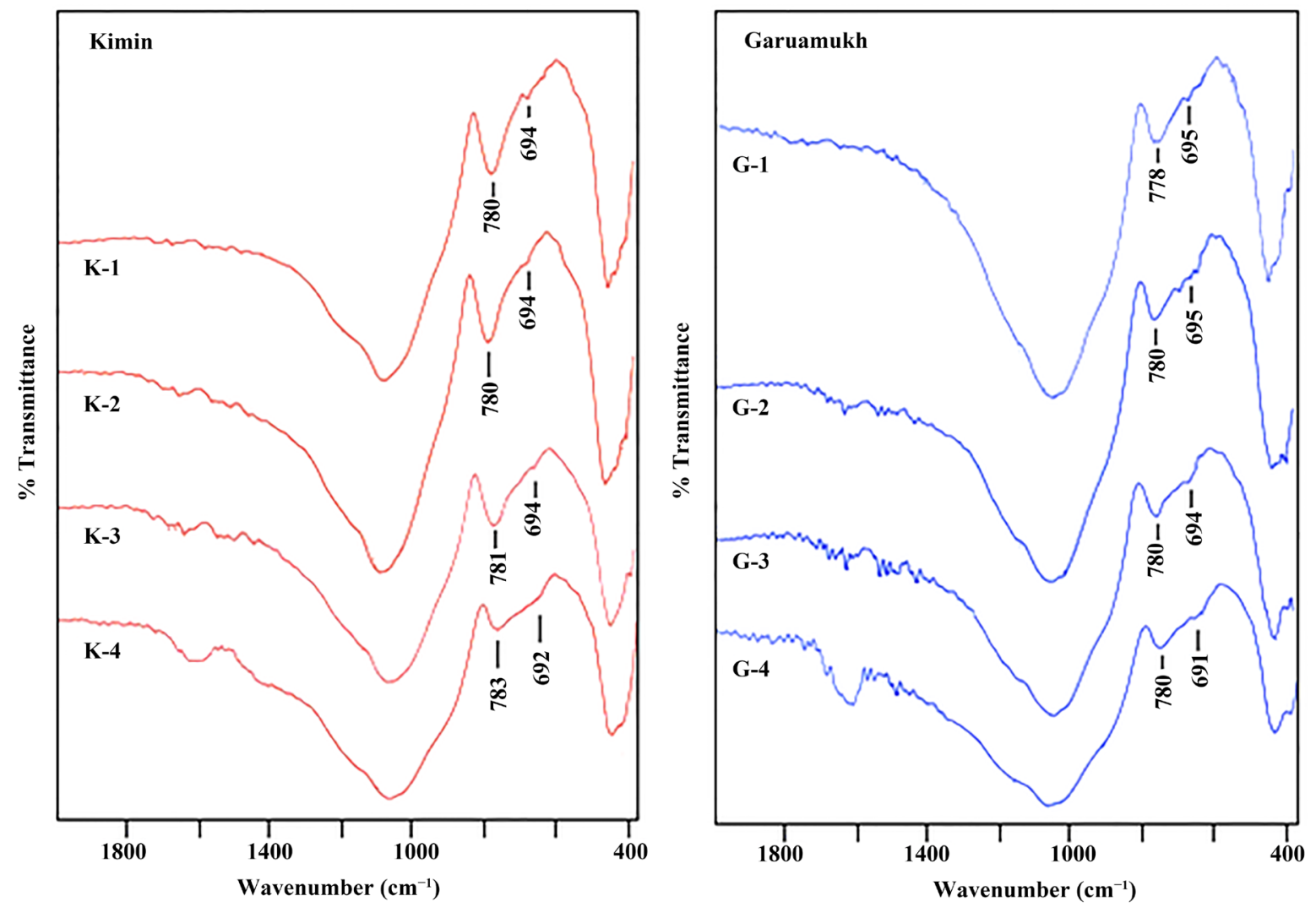

Figure 3. FTIR spectra of the Kimin and Garuamukh fulgurites in the range $2000-400 \mathrm{~cm}^{-1}$. 
A very week smash around $695 \mathrm{~cm}^{-1}$ peak in the spectra of the both fulgurites of particle size $>90 \mu \mathrm{m}$ is observed and this peak become gradually prominent as the particle size decreases to the finest range $(<45 \mu \mathrm{m})$. These variations near $695 \mathrm{~cm}^{-1}$ peak in the spectra is indicative to the presence of micro-crystalline quartz contaminants which is also identical to the X-ray diffraction.

\subsection{Distribution of Microcrystalline Quartz}

The observed increases in infrared band strengths with decreasing particle size could be due to changes of crystallinity or optical behaviour. The tetrahedral Si-O symmetrical stretching vibrational peak at $780-800 \mathrm{~cm}^{-1}$ is stronger to that of the octahedral Si-O symmetrical bending vibrational peak at $695 \mathrm{~cm}^{-1}$. Therefore, for any structural change, the damage occurs first in octahedral site symmetry then in tetrahedral site symmetry [24]-[26]. The intensity of the bands due to the vibrations of these two symmetries will provide direct information on the crystallinity. The calculated values of crystallinity index and extinction coefficient of different fraction sizes of the studied fulgurites are tabulated in Table 3. The particle size generally affects the characteristics peak of quartz [27]. At high temperature and pressure, silica polymorphs pass through a slow reconstructive recrystallization, during which existing Si-O bonds are broken and new bonds are made to allow atoms to move to appropriate positions in the more stable polymorph [28]. In glass ceramics, ceramics are produced by the controlled crystallization [29]. Any significant change in the crystallinity can be attributed to the geological conditions of formations and mechanical treatment such as grinding [30]. The optical densities of the samples are reciprocal to the calculated extinction coefficient (Table 3). Figure 4 displays the crystallinity index and extinction coefficients varies with the particle size. In the observed infrared spectra, the cryastallinity is increases as the fraction size decreases but the X-ray diffraction does not reflect such pattern.

Table 3. Calculated value of optical densities of $778 \mathrm{~cm}^{-1}$ and $695 \mathrm{~cm}^{-1}$, crystallinity indices and extinction coefficients of the different particle sizes of the fulgurites from infrared spectra.

\begin{tabular}{cccccc}
\hline Sample & $\begin{array}{c}\text { Particle size } \\
(\mu \mathrm{m})\end{array}$ & $\begin{array}{c}\text { Optical density of } \\
778 \mathrm{~cm}^{-1} \text { peak }\end{array}$ & $\begin{array}{c}\text { Optical density of } \\
695 \mathrm{~cm}^{-1} \text { peak }\end{array}$ & $\begin{array}{c}\text { Crystallinity } \\
\text { index }\end{array}$ & $\begin{array}{c}\text { Extinction } \\
\text { coefficient (K) }\end{array}$ \\
\hline G-1 & $<45$ & 0.571 & 0.544 & 1.049 & 89.69 \\
G-2 & $45-63$ & 0.566 & 0.543 & 1.041 & 88.85 \\
G-3 & $63-90$ & 0.560 & 0.540 & 1.036 & 87.98 \\
G-4 & $>90$ & 0.557 & 0.543 & 1.026 & 87.53 \\
K-1 & $<45$ & 0.628 & 0.550 & 1.142 & 98.69 \\
K-2 & $45-63$ & 0.601 & 0.537 & 1.119 & 94.41 \\
K-3 & $63-90$ & 0.590 & 0.553 & 1.066 & 92.68 \\
K-4 & $>90$ & 0.582 & 0.561 & 1.038 & 91.46 \\
\hline
\end{tabular}
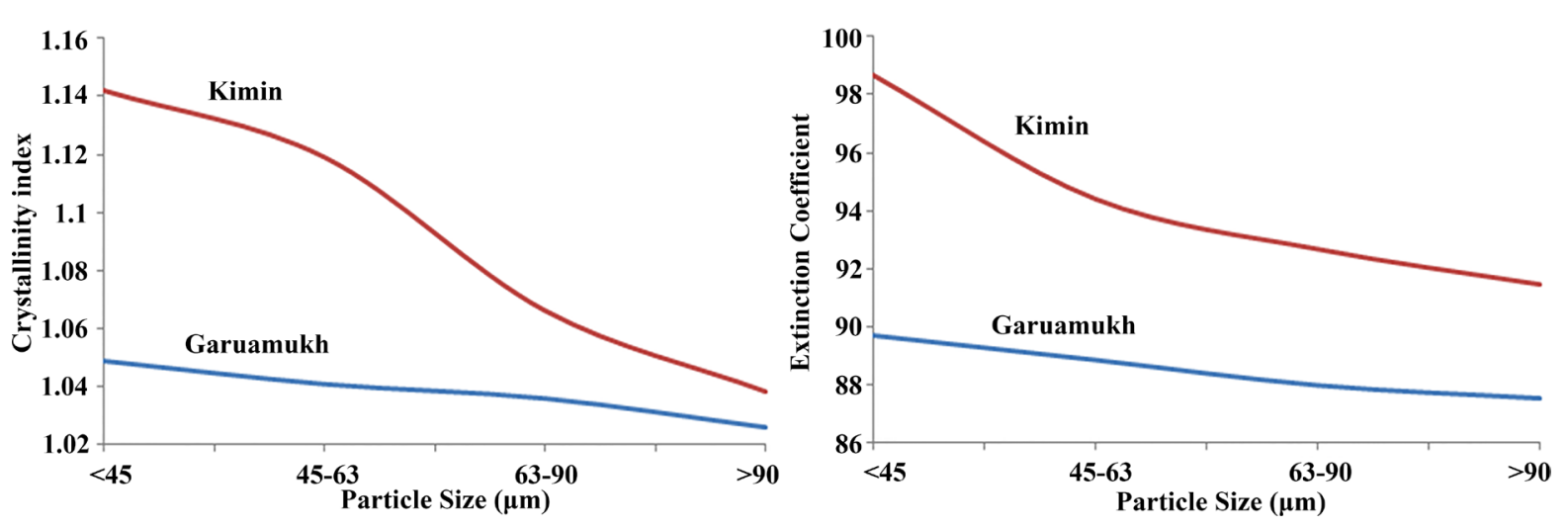

Figure 4. Variation of crystallinity index and extinction coefficient against the particle size in Kimin and Garuamukh fulgurites. 


\section{Conclusions}

The compositional and mineralogical data as determined by X-ray fluorescence spectroscopy exhibit low abundances of Ti, Na, Fe and Ca oxides, and relatively high abundances of Si and Al oxides. These abundances are consistent with the composition of the target material of the fulgurites. The X-ray diffraction pattern containing the principal peaks for microcrystalline quartz and cristobalite and the overall pattern indicates the characteristic features of amorphous silica. Due to different melting and volatilization temperatures of quartz, Al- silicates and other ground mass minerals, an enrichment of other trace minerals may observe within the glassy matrix of the fulgurites.

The infrared spectra of glassy silicate materials of fulgurites are characterized by broad features that reflect the connectivity of the $\mathrm{SiO}_{4}$ polymeric units within the three-dimensional framework of the silicate structure. Gucsik et al. also indicate the presence of the antisymmetric stretching vibration of the $\mathrm{SiO}_{4}$ tetrahedra in 1043 $1106 \mathrm{~cm}^{-1}$ region of infrared spectra of natural glasses [31]. The presence of characteristic band at approximately $695 \mathrm{~cm}^{-1}$ ( $v 2$ mode) in the infrared spectra is indicative of quartz. The frequency shifts in the Si-O symmetrical stretching vibration $(v 1)$ region of the studied infrared spectra are indicative to the presence of microcrystalline quartz. The ratio of the broad bending and stretching bands at approximately $695 \mathrm{~cm}^{-1}$ and $778 \mathrm{~cm}^{-1} \mathrm{can}^{-}$ be used to elucidate glass nanostructure, composition, as well as temperature of formation. The structural changes take place in the octahedral symmetry in the formation of the sample, so the possibility of producing this silicate glass is by ultra high-temperature that is higher than the corresponding fusion point of the crystalline state, indicating the nature of fulgurites.

When the temperature generally quenched so rapidly to $600^{\circ} \mathrm{C}-700^{\circ} \mathrm{C}$, the $\mathrm{SiO}_{4}$ tetrahedron could not be ordered to crystalline state and was preserved in an amorphous silicate phase. The presences of microcrystals in the occurrence of natural fulgurites have significant implications in the thermodynamic properties of shock metamorphism.

\section{Acknowledgements}

We thank Directors, National Geophysical Research Institute (NGRI), Hyderabad, Indian Institute of Chemical Technology (IICT), Hyderabad, North East Institute of Science and Technology (NEIST), Jorhat and G.B. Pant Institute of Himalayan Environment and Development (GBPIHED), Almora, for their cooperation during this work. We also thank Dr. J.R. Chetia, Dibrugarh University, Dibrugarh, for his assistance in the FTIR analysis.

\section{References}

[1] Krider, E.P. and Dawson, G.A. (1968) Peak Power and Energy Dissipation in a Single-Stroke Lightning Flash. Journal of Geophysical Research, 73, 3335-3339. http://dx.doi.org/10.1029/JB073i010p03335

[2] Uman, M.A. (1964) The Peak Temperature of Lightning. Journal of Atmospheric and Terrestrial Physics, 26, $123-128$. http://dx.doi.org/10.1016/0021-9169(64)90113-8

[3] Pye, K. (1982) Journal of Sediment Research, 52, 991-998.

[4] Essene, E.J. and Fisher, D.C. (1986) Lightning Strike Fusion: Extreme Reduction and Metal-Silicate Liquid Immiscibility. Science, 234, 189-193. http://dx.doi.org/10.1126/science.234.4773.189

[5] Crespo, T.M., Lozano Fernandez, R.P. and Gonzalez Laguna, R. (2009) The Fulgurite of Torre de Moncorvo (Portugal): Description and Analysis of the Glass. European Journal of Mineralogy, 21, 783-794. http://dx.doi.org/10.1127/0935-1221/2009/0021-1948

[6] Jones, B.E., Jones, K.S., Rambo, K.J., Rakov, V.A., Jerald, J. and Uman, M.A. (2005) Oxide Reduction during Triggered-Lightning Fulgurite Formation. Journal of Atmospheric and Solar-Terrestrial Physics, 67, 423-428. http://dx.doi.org/10.1016/j.jastp.2004.11.005

[7] Navarro-Gonzalez, R., Mahan, S.A., Singhvi, A.K., Navarro-Aceves, R., Rajot, J.L., McKay, C.P., Coll, P. and Raulin, F. (2007) Paleoecology Reconstruction from Trapped Gases in a Fulgurite from the Late Pleistocene of the Libyan Desert. Geology, 35, 171-174. http://dx.doi.org/10.1130/G23246A.1

[8] Schiano, P., Clocchiatti, R., Shimizu, N., Maury, R.C., Jochum, K.P. and Hofmann, A.W. (1995) Hydrous, Silica-Rich Melts in the Sub-Arc Mantle and Their Relationship with Erupted Arc Lavas. Nature, 377, 595-600. http://dx.doi.org/10.1038/377595a0

[9] Bice, D.M., Newton, C.R., McCauley, S., Reiners, P.W. and McRoberts, C.A. (1992) Shocked Quartz at the Triassic-Jurassic Boundary in Italy. Science, 255, 443-446. http://dx.doi.org/10.1126/science.255.5043.443 
[10] Haines, P.W. Jenkins, R.J.F. and Kelley, S.P. (2001) Pleistocene Glass in the Australian Desert: The Case for an Impact Origin. Geology, 29, 899-902. http://dx.doi.org/10.1130/0091-7613(2001)029<0899:PGITAD>2.0.CO;2

[11] Schultz, P.H., Zarate, M., Hames, W., Camilion, C. and King, J. (1998) A 3.3-Ma Impact in Argentina and Possible Consequences. Science, 282, 2061-2063. http://dx.doi.org/10.1126/science.282.5396.2061

[12] Stoffler, D. (1971) Coesite and Stishovite in Shocked Crystalline Rocks. Journal of Geophysical Research, 76, 54745488. http://dx.doi.org/10.1029/JB076i023p05474

[13] Stoffler, D. and Langenhorst, F. (1994) Shock Metamorphism of Quartz in Nature and Experiment: I. Basic Observation and Theory. Meteoritics, 29, 155-181. http://dx.doi.org/10.1111/j.1945-5100.1994.tb00670.x

[14] Grieve, R.A.F., Langenhorst, F. and Stoffler, D. (1996) Shock Metamorphism of Quartz in Nature and Experiment: II. Significance in Geosciences. Meteoritics and Planetary Science, 31, 6-35. http://dx.doi.org/10.1111/j.1945-5100.1996.tb02049.x

[15] Huffman, A.R. and Reimold, W.U. (1996) Experimental Constraints on Shock-Induced Microstructures in Naturally Deformed Silicates. Tectonophysics, 256, 165-217. http://dx.doi.org/10.1016/0040-1951(95)00162-X

[16] Stahle, V., Altherr, R., Koch, M. and Nasdala, L. (2008) Shock-Induced Growth and Metastability of Stishovite and Coesite in Lithic Clasts from Suevite of the Ries Impact Crater (Germany). Contributions to Mineralogy and Petrology, 155, 457-472. http://dx.doi.org/10.1007/s00410-007-0252-2

[17] Saikia, B.J., Parthasarathy, G., Sarmah, N.C. and Baruah, G.D. (2007) Geochimica et Cosmochimica Acta, 71, 866.

[18] Saikia, B.J., Parthasarathy, G., Sarmah, N.C. and Baruah, G.D. (2008) Fourier-Transform Infrared Spectroscopic Characterization of Naturally Occurring Glassy Fulgurites. Bulletin of Materials Science, 31, 155-158. http://dx.doi.org/10.1007/s12034-008-0027-z

[19] Saikia, B.J. and Sarmah, N.C. (2009) Geochimica et Cosmochimica Acta, 73, 1144.

[20] Saikia, B.J., Parthasarathy, G. and Sarmah, N.C. (2008) Fourier Transform Infrared Spectroscopic Estimation of Crystallinity in $\mathrm{SiO}_{2}$ Based Rocks. Bulletin of Materials Science, 31, 775-779. http://dx.doi.org/10.1007/s12034-008-0123-0

[21] IS 1607 (2013) Indian Standard Methods of Test Sieving. Second Revision, Bureau of Indian Standards, New Delhi.

[22] Frondel, C. (1962) Dana’s System of Mineralogy: Fulgurite. In: Encyclopaedia Britannica, John Wiley and Sons, New York, 321.

[23] Saikia, B.J. (2014) Spectroscopic Estimation of Geometrical Structure Elucidation in Natural $\mathrm{SiO}_{2} \mathrm{Crystal}_{\text {. Journal of }}$ Materials Physics Chemistry, 2, 28-33. http://dx.doi.org/10.12691/jmpc-2-2-3

[24] Ojima, J. (2003) Determining of Crystalline Silica in Respirable Dust Samples by Infrared Spectrophotometry in the Presence of Interferences. Journal of Occupational Health, 45, 94-103. http://dx.doi.org/10.1539/joh.45.94

[25] Parthasarathy, G. (2002) Effect of High-Pressures on the Electrical Resistivity of Natural Zeolites from Deccan Trap, Maharashtra, India. Journal of Applied Geophysics, 58, 321-329. http://dx.doi.org/10.1016/j.jappgeo.2005.05.008

[26] Schneider, H. (1974) Shock-Induced Thermal Transformations of Ries-Biotites. Contributions to Mineralogy and Petrology, 43, 233-243. http://dx.doi.org/10.1007/BF01134839

[27] Hlavay, J., Jonas, S., Elek, S. and Inczedy, J. (1978) Characterization of the Particle Size and the Crystallinity of Certain Minerals by IR Spectrophotometry and Other Instrumental Methods-II. Investigations on Quartz and Feldspar. Clays and Clay Minerals, 26, 139-143. http://dx.doi.org/10.1346/CCMN.1978.0260209

[28] Parthasarathy, G., Choudary, B.M., Sreedhar, B. and Kunwar, A.C. (2007) Environmental Mineralogy: Spectroscopic Studies on Ferrous Saponite and the Reduction of Hexavalent Chromium. Natural Hazards, 40, 647-655. http://dx.doi.org/10.1007/s11069-006-9015-z

[29] Beall, G.H. (1992) Design and Properties of Glass-Ceramics. Annual Review of Materials Science, 22, 91-119. http://dx.doi.org/10.1146/annurev.ms.22.080192.000515

[30] Murata, K.J. and Norman, M.B. (1976) An Index of Crystallinity for Quartz. American Journal of Science, 276, 11201130. http://dx.doi.org/10.2475/ajs.276.9.1120

[31] Gucsik, A., Zhang, M., Koeberl, C., Salje, E.K.H., Redfern, S.A.T. and Pruneda, J.M. (2004) Infrared and Raman Spectra of $\mathrm{ZrSiO}_{4}$ Experimentally Shocked at High Pressures. Mineralogical Magazine, 65, 801-811. http://dx.doi.org/10.1180/0026461046850220 